\title{
Genetic variability and structure of the Olive Field Mouse: a sigmodontine rodent in a biodiversity hotspot of southern Chile
}

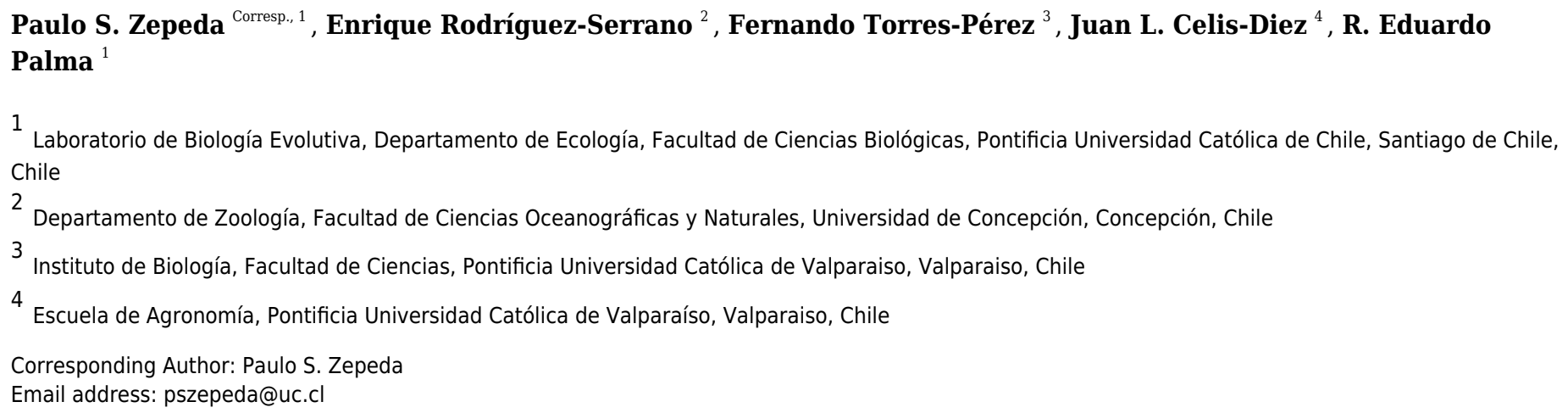

The temperate rainforests of southern Chile, a recognized biodiversity hotspot, were significantly affected by Pleistocene glacial cycles in their southern portion and have been severely disrupted mainly due to recent human activities. Additionally, the landscape is characterized by a series of potential barriers to gene flow, such as the Chacao Channel, Cordillera de Piuche in Chiloé and both the Ancud and the Corcovado gulfs. We used mitochondrial DNA sequences and microsatellite data across several populations to evaluate the genetic variability and structure of the sigmodontine rodent Abrothrix olivacea brachiotis, one of the most common species of small mammals and an inhabitant of these biodiverse forests. Sequencing data showed that along with the recovery of high haplotype variation for this species, there was a low nucleotide diversity between haplotypes, showing no genetic differences between the Chiloé Island and continental populations in southern Chile or through any other geographic barrier in the study area. However, microsatellite data exhibited some level of population structuring. The most evident clusterings were those of the Chiloé Island and that of North Patagonia. These findings are corroborated by a barrier analysis that showed a genetic barrier in the latter areas, whereas the Chacao Channel was not a significant barrier for this rodent. Overall, the genetic variability and structure of $A$. 0 . brachiotis was concordant with historical factors, such as the Last Glacial Maximum and the presence of geographic elements that isolate populations. 


\section{Genetic variability and structure of the Olive Field Mouse: a sigmodontine}

2 rodent in a biodiversity hotspot of southern Chile

3

4 Paulo S. Zepeda ${ }^{1}$, Enrique Rodríguez-Serrano ${ }^{2}$, Fernando Torres-Pérez ${ }^{3}$, Juan L. Celis-Diez ${ }^{4}$, R.

5 Eduardo Palma ${ }^{1}$

$6 \quad{ }^{1}$ Laboratorio de Biología Evolutiva, Departamento de Ecología, Facultad de Ciencias

7 Biológicas, Pontificia Universidad Católica de Chile, Santiago, Chile

$8 \quad 2$ Departamento de Zoología, Facultad de Ciencias Oceanográficas y Naturales, Universidad de

9 Concepción, Concepción, Chile

$10{ }^{3}$ Instituto de Biología, Facultad de Ciencias, Pontificia Universidad Católica de Valparaíso,

11 Valparaíso, Chile

12 Escuela de Agronomía, Pontificia Universidad Católica de Valparaíso, Valparaíso, Chile

13

14 Corresponding Author:

15 Paulo S. Zepeda ${ }^{1}$

16 Alameda 340, Santiago, Chile

17 Email address: pszepeda@uc.cl 
19 Abstract

21 The temperate rainforests of southern Chile, a recognized biodiversity hotspot, were significantly

22 affected by Pleistocene glacial cycles in their southern portion and have been severely disrupted 23 mainly due to recent human activities. Additionally, the landscape is characterized by a series of 24 potential barriers to gene flow, such as the Chacao Channel, Cordillera de Piuche in Chiloé and 25 both the Ancud and the Corcovado gulfs. We used mitochondrial DNA sequences and 26 microsatellite data across several populations to evaluate the genetic variability and structure of the sigmodontine rodent Abrothrix olivacea brachiotis, one of the most common species of small mammals and an inhabitant of these biodiverse forests. Sequencing data showed that along with the recovery of high haplotype variation for this species, there was a low nucleotide diversity between haplotypes, showing no genetic differences between the Chiloé Island and continental populations in southern Chile or through any other geographic barrier in the study area. However, microsatellite data exhibited some level of population structuring. The most evident clusterings were those of the Chiloé Island and that of North Patagonia. These findings are corroborated by a barrier analysis that showed a genetic barrier in the latter areas, whereas the Chacao Channel was not a significant barrier for this rodent. Overall, the genetic variability and structure of A. o. brachiotis was concordant with historical factors, such as the Last Glacial Maximum and the presence of geographic elements that isolate populations.

Introduction

The temperate rainforest of South America, mostly in Chile, is one of the largest areas of 42 forests in the southern hemisphere and is rich in endemic species (Veblen 2007). The region has also been named one of the 200 most important ecoregions by the World Wildlife Fund (WWF) due to the biodiversity, endemism (particularly for plants) and degree of threat (Olson and Dinnerstein 1998). These forests have been included within the 34 hotspots of biodiversity in the world (Mittermeier et al. 2004). Approximately 45\% of the pre-Columbian forest cover has been lost due to human activities (Miranda et al. 2016), being mainly replaced by crops, exotic forestry plantations (e.g., Pinus radiata and Eucalyptus spp), firewood extraction, overgrazing 
50 al. 2019). Of note, the percentage of forest loss is stronger between $39^{\circ}$ to $41^{\circ} \mathrm{S}$ in Chile, 51 reaching its lowest value at $42^{\circ} \mathrm{S}$ in the northern portion of Chiloé Island. In addition, the type 52 of vegetation replacement is different between the continent and the latter island, with more 53 exotic tree plantations in the mainland and more shrublands in Chiloe.

Historical processes have modified the landscape, creating geographic barriers among populations and changes in population sizes. Among these barriers, there are the Piuche mountain range in Chiloé Island and the Gulf of Ancud and the Gulf of Corcovado that separates the island from North Patagonia. Alternatively, the Pleistocene glacial cycles affected an important area of the landscape in the Americas, particularly the southern cone of South America. Historical records show that the temperate rainforests of the Cordillera de la Costa in Chile played a central role in maintaining higher endemism, species and genetic diversity. Because the southern portion of South America was severely affected by the Pleistocene glacial cycles (Holling and Schilling 1981, Harrison 2004), the geographical ranges of several species associated with temperate rainforests were restricted due to climatic changes triggered by glaciations. The survival of most species was restricted to small areas of oceanic influence known as "refugia." In fact, several refuge areas have been recognized in coastal areas of southcentral Chile, both for plants and animals (Villagrán and Hinojosa 1997, Sérsic et al. 2011, Segovia et al. 2012).

Within small mammals, the sigmodontine rodents (Cricetidae) are one of the most important inhabitants of the Chilean temperate rainforests, including Abrothrix olivacea (the "olive field mouse"), one of the most abundant and characteristic rodents of this biome. The species ranges from 18 to 54 S (Mann 1978; Osgood 1943; Patterson et al. 2015), encompassing areas of the Coastal Desert, the Mediterranean, the Valdivian and the Patagonian Forests and steppe. A former phylogeographic study reported strong structuring for the species, recognizing seven subspecies (Mann 1978), including Abrothrix olivacea brachiotis restricted to the temperate rainforests of southern Chile, from Valdivia $\left(39^{\circ} \mathrm{S}\right)$ southward to Aysén $\left(45^{\circ} \mathrm{S}\right)$, including the Chiloé Island and southern archipelagoes nearby (Osgood 1943; Pearson and Smith 1999; Rodríguez-Serrano et al. 2006; Patterson et al. 2015). The home range of $A$. olivacea in southern Chile is approximately 730 to $2530 \mathrm{~m}^{2}$ (González et al. 1982), which is considered high for a small rodent (25 $\mathrm{g}$ average for adult forms). The subspecies brachiotis is found in diverse types of habitats from grasses to shrubs and humid forests (Iriarte 2008). This subspecies is also 
81 found in Chiloé Island, regardless of the potential barrier that constitutes the Chacao Channel

82 (widest portion $4.6 \mathrm{~km}$ and narrowest part $1.8 \mathrm{~km}$ ). The results of nucleotide sequence analyses

83 found no genetic differences between specimens from Chiloé (Northern part) and mainland areas

84 (Rodríguez-Serrano et al. 2006). The latter pattern has also been reported for other sigmodontine 85 mice, such as Abrothrix manni (D'Elía et al. 2015), the pygmy rice-rat or long-tailed mouse 86 Oligoryzomys longicaudatus (Palma et al. 2005, 2012), and the microbiotheriid mouse opossum

87 Dromiciops gliroides (Himes et al. 2008). The opposite pattern (i.e., differentiation between the 88 continent and the island) has been reported for other species, such as the small cervid Pudu puda 89 (Fuentes-Hurtado et al. 2011), Darwin's fox Pseudalopex fulvipes (Vilà et al. 2004; Yahnke et al. 90 1996), and even for an iguanid lizard, Liolaemus pictus (Vidal et al. 2012). Leopardus guigna 91 follows the same differentiation pattern of Abrothrix olivacea, at the subspecies level, when 92 analyzed with mitochondrial sequences. However, further analyses with microsatellite data 93 showed genetic structuring, recovering a Chiloe and a continental cluster, with the Chacao 94 Channel creating a recent barrier to gene flow (approximately 8,000 years before present; 95 Napolitano et al. 2014). The latter scenario questions whether the use of a more sensitive 96 97 both continental and island (Chiloé) areas of southern Chile, we evaluated the genetic variability and structuring of Abrothrix olivacea brachiotis along its distribution in the temperate rainforests of southern Chile. In addition, we evaluated the potential effects of existing geographic barriers in the geographic distribution of A. o. brachiotis, such as the Chacao Channel, the Piuché

108 Mountains in Chiloé Island, and the border of the LMG. The ecological and evolutionary

109 features of A. olivacea populations, coupled with the hotspot of biodiversity where this species

110 lives, provides a useful model for examining historical and ecological processes that shape the 111 genetic variability and population structure of $A$. o. brachiotis. 
113 Methods

114

115 Sample collection

116

117 The study area encompasses the complete geographic distribution of the subspecies Abrothrix

118 olivacea brachiotis, between Los Rios ( $\left.40^{\circ} \mathrm{S}\right)$ and Aysen ( $\left.45^{\circ} \mathrm{S}\right)$ regions in the temperate

119 rainforest ecoregion (green shade with black stripes, Fig. 1). We sampled 11 localities with at

120 least 2 sampling points, except for Chiloé National Park (Cucao), which had a single site (Fig. 1;

121 see Table S1 for sampled localities). The sampling gap between the southernmost localities on

122 the continent was due to the geographic difficulties in accessing that area for fieldwork.

123

124 Most of the tissues used in this study were retrieved from A. o. brachiotis voucher 125 specimens deposited in the Colección de Flora y Fauna "Profesor Patricio Sánchez Reyes"

126 (SSUC), Departamento de Ecología, Pontificia Universidad Católica de Chile, Santiago, Chile, 127 and in the Museum of Southwestern Biology (MSB), Department of Biology, University of New

128 Mexico, Albuquerque, New Mexico, USA. The remainder of the samples were the result of field 129 campaigns in which standard Sherman traps were used $(8 \times 9 \times 23 \mathrm{~cm}$; H. B. Sherman Traps, 130 Inc., Tallahassee, FL, USA) with oats and vanilla as bait. Fieldwork protocols followed the 131 standard bioethical and biosafety protocols outlined by the American Society of Mammologists 132 (ASM; Sikes and Gannon 2011), and the Centers for Disease Control and Prevention (CDC; 133 Mills et al. 1995), respectively. All of the new rodent captures were deposited at SSUC. The 134 captures were conducted under the Chilean Government authorization (Servicio Agricola y

135 Ganadero; SAG): Resolución Exenta \#5675/2013 and the approval of the Bioethics Committee

136 of Pontificia Universidad Católica de Chile (\#CBB-220/2012). A detailed list of specimens

137 sequenced per locality is given in Table S1. A total of 187 samples were used in this study. All

138 of them were genotyped for microsatellite loci, and a subset of 107 samples was sequenced for

139 the mitochondrial hypervariable region I (HVI) analyses (see Table S1 for samples sequenced 140 and genotyped).

142 Laboratory procedures 


\section{DNA Extraction}

145 DNA was extracted from either frozen tissues $\left(-80^{\circ} \mathrm{C}\right)$ or ethanol preserved tissues (liver, lung or 146 kidney) using the Wizard Genomic DNA Purification Kit (PROMEGA, Madison, Wisconsin) or 147 the Phenol-Chloroform protocol (modified from Sambrook, Fritsch \& Maniatis, 1989).

149 Mitochondrial DNA

150 Through the polymerase chain reaction (PCR), we amplified the complete hypervariable domain

151 I (HVI) of the mtDNA control region, using primers and protocols outlined in Rodríguez-Serrano 152 et al. (2006). A total of 483 base pairs (bp) of the HVI region from 92 individuals were 153 sequenced and then deposited at the GenBank database (accession numbers: MH714355 to 154 MH714446). In addition, another 15 sequences of the subspecies Abrothrix olivacea brachiotis 155 were obtained from GenBank (Accession numbers: AY840064 to AY840078). We thus 156 completed a total of 107 sequences that were aligned using the Clustal W program (Larkin et al. 157 2007) implemented in the software BIOEDIT (Hall 1999). All samples were sequenced in 158 MACROGEN Inc. (Seoul, Korea).

Microsatellite DNA

161 A total of 28 microsatellite primer pairs were specially designed for this study through the 162 company Genetic Marker Services Laboratories (London, UK). Following the manufacturer's 163 instructions, we standardized only those that presented good quality in the report given by the 164 company. A subset of 16 SSR was screened for polymorphisms and then tested for genotyping 165 problems in Microchecker (van Oosterhout et al. 2006). After these tests, 12 loci were the final 166 set of primers used in this study (Table S2). Using the program FSTAT version 2.9.3.2 (Goudet 167 1995), we tested for linkage disequilibrium between pairs of loci. PCR conditions were 168 standardized specifically for these newly designed primers with a protocol in a $10 \mu$ reaction 169 volume containing $2 \mu \mathrm{l}$ of Buffer $5 \mathrm{X}, 2 \mu \mathrm{l}$ of $\mathrm{MgCl} 2$ at $25 \mu \mathrm{g} / \mu \mathrm{l}, 1 \mu \mathrm{l}$ of dNTPs at $2 \mu \mathrm{g} / \mu \mathrm{l}, 0.25$ $170 \mu \mathrm{l}$ of BSA, $0.2 \mu \mathrm{l}$ of forward primer and $0.2 \mu \mathrm{l}$ of reverse primer, $0.35 \mu 1$ of M13 fluorescence 171 tail, $0.15 \mu \mathrm{l}$ of Taq polymerase, and finally $2 \mu \mathrm{l}$ of DNA at $40 \mathrm{ng} / \mu \mathrm{l}$. Each pair of primers was 172 standardized to a thermocycler protocol with 32 cycles of 1 min denaturation at $95^{\circ} \mathrm{C}$, annealing 
173 of $1 \mathrm{~min}-2$ cycles each $65-59^{\circ} \mathrm{C}, 10$ cycles at $58^{\circ} \mathrm{C}, 10$ cycles at $57^{\circ} \mathrm{C}$, an elongation of $1 \mathrm{~min}$

174 at $72{ }^{\circ} \mathrm{C}$, and a final extension at $72^{\circ} \mathrm{C}$ for $5 \mathrm{~min}$ (Table S2).

175 Microsatellites were fragment analyzed in an ABI3500 and then genotyped with the software

176 GENEMAPPER (GeneMapper ${ }^{\circledR}$ v4.0; Applied Biosystems ${ }^{\circledR}$, Foster City, CA, USA). In the

177 standardization process, at least 8 samples of different localities were repeated to ensure

178 consistency in the genotyping process. Additionally, the dataset was analyzed with the software

179 Microchecker (van Oosterhout et al. 2006) for testing allelic dropout and null alleles.

180

181 Analyses of genetic structure and variability

182

183 Mitochondrial DNA

184

185 To examine population dynamics, we used Tajima's test of neutrality (Tajima 1989). Assuming 186 that sequence variation in the control region was neutral, we calculated the Tajima's D index to test the occurrence of population expansion if the values obtained indicated a significant negative value or a population equilibrium. To assess the population structure, a median-joining haplotype network was generated based on the HVI sequence dataset, using the software popART 1.7

190 (Leigh \& Bryant 2015; Bandelt 1999). The graph was calculated and plotted using the median191 joining algorithm. Genetic diversity and variability were measured calculating haplotype (Hd) 192 and nucleotide $(\pi)$ diversity using popART 1.7 (Leigh \& Bryant 2015; Bandelt 1999) (Table 1).

Microsatellite DNA

195 Genetic diversity indexes were calculated with the software GENODIVE (Meirmans and 196 Tienderen 2004) and HPrare (Kalinowski 2005). We thus calculated the observed and expected 197 heterozygosity, the number of alleles (A) and the number of alleles standardized to the 198 population with the smallest sample size (Ar). Additionally, with the software NeEstimator (Do et al. 2014), we estimated the effective population size (Ne) for each of the clusters calculated with the Structure software (see below) using the linkage disequilibrium method (Hill 1981; Table 1). Deviations from the Hardy-Weinberg equilibrium were examined for each population at each locus calculating the fixation index Fis with the software GENODIVE. Genetic differentiation was assessed with pairwise Fst values between populations (Table S3). 
204 Isolation by Distance (IBD) was calculated through a Mantel test with GenAIEx software (v6.5;

205 Peakall and Smouse 2012). To run this program, we generated a geographic distance matrix and

206 a Nei's Index for obtaining a genetic distance matrix. Significance was tested using 9,999

207 permutations.

208 We used the Structure software (Prichard et al. 2000) to define population genetic

209 structure without assuming a priori knowledge of sampling location or number of populations.

210 To determinate the number of clusters, we used 10,000,000 iterations with a burn-in of 1,000,000

211 simulations. We evaluated $\mathrm{K}$ among 1 to 8 clusters, and each was run 10 times to ensure the

212 stability and variance of likelihood values. Admixture and correlation models were used. These

213 models assume mixed ancestry for all analyzed individuals and where the allele frequencies of

214 closely related populations may be correlated. To determine the most likely K of our sample, we

215 used the approach of Evanno implemented in the web platform Clumpak (Kopelman et al. 2015)

216 (Evanno et al. 2005). In this platform, the second-order rate of change of the log probability of

217 data with respect to the number of clusters was examined. The same platform delivers a graphic

218 and color representation that combines runs.

219 We performed GENELAND analyses (Guilliot et al. 2005) considering the microsatellite

220 genetic data plus the spatial location of samples. This approach is a Bayesian cluster analysis that

221 uses individual geo-referenced genetic data to detect the number and geographic position of

222 populations (Guilliot et al. 2008). The algorithm identifies genetic discontinuities while

223 estimating both the number and locations of populations without any a priori knowledge on the

224 population units and limits. Once the number and limits of populations were established, the

225 population membership probability was calculated from the posterior probability distribution of

226 the MCMC. First, one independent run was performed by 10,000,000 iterations, sampling every

227 1,000 iterations of the Markov Chain and treating the number of populations as unknown varying

228 between $\mathrm{K}=1$ to 8 . Then, we chose the better of 20 independent runs, each of $10,000,000$

229 generations and sampling every 1,000 but now treating the number of populations as a fixed

230 parameter estimated from the first independent run. We used the admixture model and correlated

231 allele frequencies to estimate the posterior probability of the data with $1 \mathrm{~km}$ of uncertainty to

232 detect possible different clusters of samples with shared localities. From the posterior

233 distribution, we drew a map of probability isoclines of population membership, one for each

234 population or cluster inferred by the model. With this result, a map with the geographic limit was 
235 elaborated using QGIS (QGIS Development Team (2019). QGIS Geographic Information

236 System. Open Source Geospatial Foundation Project. http://qgis.org).

237 The software Barriers (vs 2.2, Manni et al. 2004) was used to test the occurrence of

238 genetic barriers between different localities. This program uses a Monmonier's algorithm with

239 Delaunay triangulation. The significance of a detected barrier is the result of 1000 sub replicates,

240 and the matrices of pairwise differences were generated by the software MSAT (Dieringer \&

241 Scholotterer 2003). For this analysis, a barrier was considered valuable when we obtained

242 bootstrap values over $90 \%$ (Fig. 1).

243

244 Results

245 Mitochondrial DNA Data Analysis

246 The haplotype gene diversity (Hd) was 0.965 (variance 0.00007), the nucleotide diversity (Pi)

247 was 0.01070 , and the Tajima index calculated over the mitochondrial data showed a value of -

$2481.84(0.1 \mathrm{p}>0.05)$, which is not significant, meaning that populations exhibited neutrality.

249 The median-joining network recovered 56 haplotypes (Fig. 2) for the $107 \mathrm{mtDNA}$

250 sequences of the HVI mtDNA region. Figure 2 shows a group of haplotypes of low frequency

251 and few mutational steps (between 1-3) from Cucao ("purple") in Chiloé Island. Another

252 clustering of haplotypes ("red") was observed with samples from Senda Darwin Biological

253 Station in the north of Chiloé Island. Some of these haplotypes exhibited high frequencies with

254 up to 8 sequences but with low mutational steps (the highest with 5 steps). There is a shared

255 haplotype of high frequency (13 sequences) that recovered localities from the mainland and the

256 Chiloé Island. In addition, the Valdivian localities had haplotypes that spread throughout the

257 network; these haplotypes were of low frequencies, with few mutational steps (1-3) and related

258 to localities of Mininco and Río Blanco in the southernmost distributional range of $A$. $O$.

259 brachiotis in northern Patagonia. At this latter point, a high frequency haplotype (11 sequences)

260 was recovered that included the two latter localities of Mininco and Rio Blanco. Other

261 haplotypes ("turquoise," "gray" and "green;" see legend Fig. 2) represent north-continental

262 localities that are connected among them with few mutational steps and low frequencies.

263

264 Microsatellite data analysis 
265 Results from Microchecker showed that loci Aol44, Aol55B, Aol91 and Aol52B deviated from

266 Hardy-Weinberg equilibrium with heterozygosity deficiency. This was the case for only a single

267 population per locus, and for this reason, data were not removed from the analysis. None of the

268 populations revealed heterozygosity excess, and Microchecker did not identify genotyping

269 errors, null alleles, or allele dropout in our data. There was no significant genotypic linkage

270 disequilibrium detected for any pair of loci.

271 In Table 1, we show the genetic diversity for microsatellite data per localities. We

272 considered 11 populations and pooled Palena with Santa Lucia due to the geographic proximity

273 of the size of these two populations. Ho and He were similar except in La Picada, but this may be

274 due to the low sample size. The FST index calculated between all populations gave a majority of

275 significant differences between populations with the exception of La Picada vs. the rest, but this

276 may also be due to a low sampling size. Additionally, the Mantel correlation coefficient, the test

277 for isolation by distance, was positive $(\operatorname{Rxy}=0.386, \mathrm{p}=0.01$; Figure 3$)$, giving a positive and

278 significant correlation between genetic and geographic distance.

279 We observed that the highest number of alleles was concentrated between the mainland

280 and Senda Darwin Biological Station in Chiloé, although the Cucao and North-Patagonian

281 populations also concentrated an important number of alleles. The effective number of alleles

282 (corrected with the sample size) was higher in the continent than in Chiloé Island and North-

283 Patagonian populations. The same Table 1 shows no significant differences between observed

284 and expected heterozygosity values for all localities, showing high values (all of them near 0.8);

285 Gis values were significant for all 4 localities.

286 Figure 4 shows the results of STRUCTURE analysis. The Evanno method (Evanno et al.

287 2005) recovered five clusters $(K=5)$ with the highest probability (Fig. 4C). From north to south,

288 clusters 1 and 2 grouped populations from Panguipulli, Valdivia, Bahía Mansa, La Picada and

289 Las Quemas ("purple" and "yellow"); cluster 3 ("blue") included mainly populations from Senda

290 Darwin Biological Station (north of Chiloé Island); cluster 4 ("orange") constitutes the Cucao

291 population (central Chiloé at Chiloé National Park), and the last cluster ("green”) included

292 southern populations of Palena, Santa Lucía, Río Simpson, Mininco and Alto Río Ibañez in

293 North Patagonia. Clusters 1 and 2 ("yellow" and "purple") recovered an intermingling of

294 probabilities for continental populations from the northernmost distribution of $A$. o. brachiotis,

295 from Panguipulli to Las Quemas. However, some individuals from Panguipulli were assigned to 
296 the orange cluster. The second highest supported $\Delta \mathrm{K}$ recovered 3 clusters (Fig. 4A), identifying 297 the same clusters showed in K = 5: "blue," "orange" and "green," whereas individuals from the 298 continent (clusters "yellow" and "purple") were assigned to clusters "orange" and "blue." We 299 also show analysis with $\mathrm{K}=4$, exhibiting the same pattern, with coastal south temperate forest 300 populations forming a not well defined cluster, two clusters in Chiloé Island, and another 301 grouping the populations of North Patagonia.

302 Even though $\mathrm{K}=5$ clusters with the highest probability, $\mathrm{K}=4$ has greater biological sense.

303 Following this finding, we estimated the effective size of $K=4$ obtained with Structure

304 (Continental, Senda Darwin, Cucao and North Patagonia). The biggest effective size was in the

305

306

307

308

309

310

311

312

313

314

315

316

317

318

319

320

321

322

323

324

325

326 continent with 683.3, followed by Senda Darwin with 274.9; the smallest cluster was Cucao with 54 individuals. In the mainland, the top limit of the confidence interval is infinite (Table 1).

The population structure for A. olivacea brachiotis was also evaluated using the GENELAND v. 1.0.7 program. This analysis inferred three genetic clusters in the study area. A first cluster (Fig. 5A) mostly grouped individuals representing localities of continental Chile and the northern portion of the Chiloé Island. A second cluster joined individuals representing localities of Panguipulli and Cucao (Fig. 5B), and a third cluster grouped all southernmost populations (Fig. 5C). All clusters presented 0.65 of probability in the isocline that grouped the populations.

The program Barriers corroborated the genetic isolation of clusters by barriers. In fact, a strong barrier is hypothesized between populations of North Patagonia and the rest of brachiotis' distribution with $100 \%$ of appearance with 1000 replicas, and a second barrier was proposed in Chiloé Island between Senda Darwin Biological Station and Cucao. Both proposed barriers exhibited high levels of consistency when we performed the analysis with 1000 replicates.

\section{Discussion}

Using both mitochondrial and microsatellite markers, we evaluated the structuring and variability across the distribution of Abrothrix olivacea in the temperate rainforests of Southern Chile. Our results corroborated the phylogeographic study of Rodriguez-Serrano et al. (2006), which showed no difference when comparing populations of $A$. o. brachiotis between Chiloé Island and the mainland using mitochondrial sequences. In the present study, we recovered two new 
327 haplogroups, one in the south of Chiloé (Cucao) that shares haplotypes with the continent, and

328 the North Patagonia haplogroup that included populations of Mininco and Alto Rio Ibañez

329 (ARI). The last haplogroup had one shared haplotype between Valdivia (Northern continental

330 distribution) and Mininco, and few mutational steps with other Valdivian haplotypes. In

331 summary, the mitochondrial analysis showed low genetic structuring for the subspecies

332 brachiotis and the nonoccurrence of exclusive haplotypes for any of the localities and recovered

333 shared haplotypes with North continental localities. The overall mtDNA network had low

334 nucleotide diversity, meaning that besides the high number of haplotypes (high haplotype

335 diversity), there were little differences between them.

336 The Microsatellite Genetic diversity indices showed that across all populations sampled

337 (11), there were no significant differences and that Ho versus He was similar with the exception

338 of La Picada, although this may be due to small sample size. The pairwise Fst showed that only

339 close localities did not show significant differences, such as Mininco with Rio Simpson in North

340 Patagonia. This finding is consistent with the pattern of isolation by distance found in the data.

341 Additionally, the La Picada population, when compared with other localities, did not show (in

342 general) significant differences, most likely due to small sample size.

In general, the number of alleles standardized for the sample size revealed that across

344 populations, they all have similar values of allelic richness (7.20-10.45). The only population

345 that exhibited a lower number of alleles was La Picada (4.33). When populations were grouped

346 into 4 clusters (Continental, Senda Darwin, Cucao and North Patagonia), the difference was even

347 smaller (8.70-10.53). Senda Darwin in Chiloé had the lowest allelic richness and the continental

348 groups had the highest. This fact may be due to the recent separation of this population (Senda

349 Darwin) from the continent. High continental allelic richness may explain the different sources

350 of alleles: more than one refuge represents the genetic diversity of this cluster. In fact, this cluster

351 also exhibits the highest number of private alleles. In the case of $A$. o. brachiotis, we did not find

352 a heterozygosity deficit in any of the localities, as there were no significant differences when

353 comparing mainland and island populations. Thus, it seems that despite recent intense forest

354 fragmentation and degradation (Echeverría et al. 2006), the habitat for A. o. brachiotis does not

355 seem to be a critical factor for the genetic variability, as it can adapt to new vegetational types to

356 preserve heterozygosity (Murúa and González 1982; Murúa \& González 1986; Patterson et al.

357 1990; González et al. 2000). 
Microsatellite data analyzed across A. o. brachiotis's geographic range recovered five

359

360

361

362

363

364

365

366

367

368

369

370

371

372

373

374

375

376

377

378

379

380

381

382

383

384

385

386

387

388

genetic clusters with Structure, with those results having the highest probability through the Evanno method. Two of these clusters corresponded to populations from the mainland, two others corresponded to populations from Chiloé Island, and a single cluster was restricted to the southernmost limit of the subspecies range in the North Patagonian forests (Aysen region). The clusters recovered in the continent ("yellow" and "purple;" Fig. 4c) were not well defined, and individuals were not assigned to a single cluster. They had mixed probabilities belonging to one or another cluster ("yellow" or "purple"), suggesting that these populations maintained their genetic variation and served as a source of alleles for other clusters (Omote et al. 2012). In an LGM scenario, particularly during the interglacial period, coastal refugees and dispersalist populations of iced eastern localities may have dispersed back to central depression and preAndean areas in southern Chile (e.g., Panguipulli area). This may have allowed the intermingling of coastal and eastern populations as suggested by the pattern of the current Structure analysis (Sérsic et al. 2011). The pattern of structure for the mainland agreed with the high allelic richness and number of private alleles, due to the composition of genetic diversity of the area, on which more than one refugia has been recognized, which might suggest the source of variation.

The structuring of $A$. o. brachiotis within Chiloé is more evident. We recognized two genetic clusters in the island, one represented by the northern population of Senda Darwin Biological Station, and the other represented in the west-central portion of the island, the Chiloé National Park at Cucao. These genetic structures of $A$. o. brachiotis in Chiloé might be explained by different but not mutually exclusive causes, such as the Cordillera de Piuché (a portion of the Coastal Cordillera that separates the Chiloé National Park from the northernmost portion of the island where the Senda Darwin Biological Station is located), and the major town of Castro (Chiloé's capital city) towards the east of the Coastal Cordillera. Other additional barriers that might have isolated the Cucao area from the rest of the island are historical events, such as the glacial border of the LGM during the Pleistocene that advanced throughout the island. This glacial border left a refuge area in northwest Chiloé where a portion of the National Park is located (Rabassa and Claperton 1990, Moreno et al. 2015; Fig. 1). These current and historical factors might have contributed to the existing genetic structure of A. o. brachiotis populations within the island. To the southeast of Chiloé, in the mainland, the North Patagonian structuring of Abrothrix in Palena and Aysén may be explained by isolation by distance: their geographic

Peer) reviewing PDF | (2018:08:30427:3:2:NEW 9 Apr 2019) 
389 isolation with respect to Chiloé, and the geographic distance with respect to mainland

390 populations located to the north. These facts, coupled to the glaciation of the LGM that

391 completely covered these populations, might have forced $A$. o. brachiotis to find refuge areas

392 separated from other populations.

393 The effective size of the different clusters is consistent with the size of the localities. We

394 have the largest population in the mainland cluster that has a wide range of sampling points.

395 Moreover, Cucao is estimated as the smallest Ne and is the population that shows the sharpest

396 isolation, with the Piuche Mountains on one side, and the condition of glacial refugia. Of note,

397 the analysis estimated that the continental cluster has the highest effective size. However, its

398 upper limit as infinite could be due to a large effective size, or a limitation of our dataset, considering that this cluster is the largest, and it may need a more exhaustive sampling.

Geneland analyses, on the other hand, recovered 3 clusters. One cluster is shared by

401

402

403

404

405

406

407

408

409

410

411

412

413

414

415

416

417

418

419

populations of the continent and Senda Darwin Biological Station in Chiloé Island. This cluster sustains the hypothesis that the Chacao Channel is a recent barrier for Abrothrix since the sea level descended during LGM, allowing for a glacial bridge between Chiloé and the continent, generating a refuge area in the coast of the Chile Lake district (Sérsic et al. 2011). Genetic connectivity between Chiloé and the continent have been inferred for other mammals, such as the microbiotheriid mouse opossum Dromiciops gliroides (Himes et al. 2008), the long-tailed sigmodontine mouse Oligoryzomys longicaudatus (Palma et al. 2012), the sigmodontine Abrothrix manni (D'Elía et al. 2015), and even the iguanid lizard Liolaemus pictus (Vidal et al. 2012a; b). Geneland also recovered two different cluster populations in the island, one to the north of Chiloé (Senda Darwin) and the other in central west Chiloé (Cucao), consistent with the results of Structure. The latter agreed with the hypothesis of refuge for Cucao and the effective barrier that constitutes the Piuché Mountains. Finally, the third cluster is the same that Structure analysis recovered for North Patagonia populations.

Finally, the Barrier analysis (Manni et al. 2004) corroborated the occurrence of a genetic barrier due to the Cordillera de Piuché in Chiloe. The same analysis hypothesized the existence of a barrier between North Patagonia populations and the rest of brachiotis' distribution. Both barriers might also be inferred with Structure analysis (a distinctive cluster for northern Chiloé,

18 Cucao and North Patagonia) and with Geneland, which show clusters that are separated by the aforementioned barriers. The Barrier analysis also demonstrated that the Chacao Channel would 
420 not be a genetic barrier for A. o. brachiotis, and these results are consistent with those of

421 Geneland (Fig. 5A)

422

423 Conclusions

424

425

In this study, we obtained a subtle structuring of populations at the northern portion of the continental range of $A$. o. brachiotis, which is more evident in Chiloé with two major clusters within the island. An additional structuring was recovered in the northern portion of the Patagonian range of A. o. brachiotis. Our results seem to suggest that $A$. olivacea and particularly A. o. brachiotis restricted to the temperate rainforests of southern Chile, reacts more to historic than to ecological events regarding its genetic population dynamics and that interruptions of connectivity (Chacao Channel) would not constitute a genetic barrier for this rodent. The genetic structuring observed would respond to the geographic and long dated isolation of populations, as observed by the presence of Cordillera de Piuché that isolated populations in north Chiloé (Senda Darwin) with respect to those of Parque Nacional Chiloé (Cucao). In addition, populations from the latter geographic area are located in what was a glacial refuge during the Pleistocene. North Patagonian populations, on the other hand, may constitute a genetic clustering due to their isolation with respect to Chiloé populations and the geographic distance from the northern range of this subspecies. This isolation might be enhanced by geographic barriers, such as both the gulfs of Ancud and Corcovado and the mountain range of the Andes.

\section{Acknowledgments}

442

We acknowledge the laboratory support of R. A. Cancino and M. P. de Castro from the FONDEQUIP EQM150077; same Department) for her support with the genotyping analyses.

\section{References}


452 Bandelt, H.J.; Forster, P.; Röhl, A. (1999) Median-joining networks for inferring intraspecific 453 phylogenies. Mol Biol Evol 16:37- 48

454 455

456

457

458

459

460

461

462

463

464

465

466

467

468

469

470

471

472

473

474

475

476

477

478

479

480

481

Bowman, D,M,J.S.; Moreira-Muñoz, A.; Kolden, C.A.; Chávez, R.O.; Muñoz, A.A.; Salinas, F.; González-Reyes, Á.; Rocco, R.; de la Barrera, F.; Williamson, G.J.; Borchers, N.; Cifuentes, L.A.; Abatzoglou, J.T. \& Johnston, F.H. (2019) Human-environmental drivers and impacts of the globally extreme 2017 Chilean fires. Ambio. 48:350.

Cavelier, J. \& Tecklin, D. (2005) Conservación de la cordillera de la costa: Un desafio urgente de la ecoregión valdiviana (pp. 632-641). In: Smith, C.; Ramírez, C.; Armesto, J. \& Valdovinos, C., editors. Historia, 23 biodiversidad y ecología del bosque costero de Chile. Editorial Universitaria, Santiago, Chile.

D’Elía, G.; Teta, P.; Upham, N.S.; Pardiñas, U.F.J. \& Patterson, B.D. (2015) Description of a new soft-haired mouse, genus Abrothrix (Sigmodontinae), from the temperate Valdivian rainforest. J Mammal. 96: 839-853.

Dieringer, D. \& Schlötterer, C. (2003). Microsatellite analyser (MSA): a platform independent analysis tool for large microsatellite data sets. Mol Ecol Notes. 3: 167-169.

Do, C.; Waples, R.S.; Peel, D.; Macbeth, G.M.; Tillet, B.J. \& Ovenden, J.R. (2014) NeEstimator V2: reimplementation of software for the estimation of contemporary effective population size (Ne) from genetic data. Mol Ecol Resour. 14:209-214.

Echeverría, C.; Newton, A. C.; Lara, A.; Benayas, J. M. R. \& Coomes, D. A. (2007) Impacts of forest fragmentation on species composition and forest structure in the temperate landscape of southern Chile. Global Ecol Biogeogr. 16: 426-439.

Evanno, G.; Regnaut, S. \& Goudet, J. (2005) Detecting the number of clusters of individuals using the software structure: a simulation study. Mol Ecol. 14: 2611-2620.

Frankham, R. (1996) Relationship of genetic variation to population size in wildlife. Conservation Biology, 10: 1500-1508.

Frankham, R.; Ballou J.D. \& Briscoe, D.A. (2002) Introduction to Conservation Genetics. Cambridge University Press, Cambridge.

Fuentes-Hurtado, M.; Marín, J.C.; González-Acuña, D.; Vergudo, C.; Vidal, F. \& Vianna, J. (2011) Molecular divergence between insular and continental Pudu deer (Pudu puda) populations in the Chilean Patagonia. Stud Neotrop Fauna E. 46: 23-33. 
482 González, L.A.; Murúa, R. \& Feito, R. (1982) Densidad poblacional y padrones de actividad

483

484

485

486

487

488

489

490

491

492

493

494

495

496

497

498

499

500

501

502

503

504

505

506

507

508

509

510

511

512

espacial de Akodon olivaceus (Rodentia, Cricetidae) en hábitats diferentes (pp. 935-947). In: Salinas, P., editor. Actas de Séptimo Congreso Latinoamericano de Zoología, Zoología Neotropical, Mérida, Venezuela.

González, L.A; Murúa, R. \& Jofré, C. (2000) Habitat utilization of two muroid species in relation to population outbreaks in southern temperate forests of Chile. Rev Chil Hist Nat. 73: 489-495.

Goudet, J. (1995) FSTAT version 1.2: a computer program to calculate F-statistics. J Hered. $86: 485-486$

Guilliot, G.; Mortier, F. \& Estoup, A. (2005) Genelad: A computer package for landscape genetics. Mol Ecol Notes. 5: 712-715.

Guilliot, G.; Santos, F. \& Estoup, A. (2008) Analysing georeferenced population genetics data with Geneland: A new algorithm to deal with null alleles and a friendly graphical user interface. Bioinformatics. 24: 1406-1407.

Hall, T.A. (1999) BioEdit: a user-friendly biological sequence alignment editor and analysis program for Windows 95/98/NT. Nucleid Acids Symp. Ser. 41: 95-98.

Harrison, S. (2004). The Pleistocene glaciations of Chile. Quaternary Glaciations-Extent and Chronology. Part III: South America, Asia, Africa, Australasia, Antarctica, edited by: Ehlers, J. and Gibbard, PL, Cambridge.

Himes, C.M.T.; Gallardo, M.H. \& Kenagy, G.J. (2008) Historical biogeography and post-glacial recolonization of South American temperate rain forest by the relictual marsupial Dromiciops gliroides. J Biogeogr. 35: 1415-1424.

Holling, J.T. \& Schilling, D.H. (1981) Late Wisconsin-Weichselian mountains glaciers and small ice caps (pp 179-206). In: Denton, G.H. \& Hughes, T.J. editors. The last great ice sheets. John Wiley \& Sons, New York, USA.

Iriarte, W.A. (2008) Mamíferos de Chile. Lynx edicions, Barcelona, España.

Kalinowski, S.T. (2005). hp-rare 1.0: a computer program for performing rarefaction on measures of allelic richness. Mol Ecol Notes. 5: 187-189.

Kopelman, N.M.; Mayzel, J.; Jakobsson, M.; Rosenberg, N.A. \& Mayrose, I. (2015). Clumpak: a program for identifying clustering modes and packaging population structure inferences across K. Mol Ecol Resour. 15: 1179-1191.

Peer) reviewing PDF | (2018:08:30427:3:2:NEW 9 Apr 2019) 
513 Lara, A.; Solari, M.E.; Prieto, M.R. \& Peña, M.P. (2012) Reconstrucción de la cobertura de la 514 vegetación y uso del suelo hacia 1550 y sus cambios a 2007 en la ecorregión de los 515 bosques valdivianos lluviosos de Chile ( $35^{\circ}-40^{\circ} 30^{\prime}$ S). Bosque. 33: 13-23.

516 Larkin, M. A.; Blackshields, G.; Brown, N. P.; Chenna, R.; McGettigan, P. A.; McWilliam, H.; 517

518 ... \& Thompson, J. D. (2007) Clustal W and Clustal X version 2.0. bioinformatics, 23: 2947-2948.

Leigh, J.W. \& Bryant, D. (2015). popart: full-feature software for haplotype network construction. Methods in Ecology and Evolution, 6: 1110-1116.

Mann, G. (1978). Los pequeños mamíferos de Chile: marsupiales, quirópteros, edentados y roedores. Gayana Zoologia, 40: 1-342.

Manni, F.; Guérard, E. \& Heyer, E. (2004). Geographic patterns of (genetic, morphologic, linguistic) variation: how barriers can be detected by "Monmonier`s algorithm". Hum Biol, 76:173-190.

Meirmans, P.G., \& Van Tienderen, P.H. (2004). GENOTYPE and GENODIVE: two programs for the analysis of genetic diversity of asexual organisms, Mol Ecol Notes 4: 792-794.

Mills, J.N.; Yates, T.L.; Childs, J.E.; Parmenter, R.R.; Ksiazek, T.G.; Rollin, P.E. \& Peters, C.J. (1995) Guidelines for working with rodents potentially infected with Hantavirus. J Mammal. 76: 716-722.

Miranda, A.; Altamirano, A.; Cayuela, L.; Lara, A., \& González, M. (2017). Native forest loss in the Chilean biodiversity hotspot: revealing the evidence. Reg Environ Change. 1: 285297.

Mittermeier, R.A.; Robles Gil, P.; Hoffman, M.; Pilgrim, J.; Brooks, T.; Goettsch Mittermeier, C.; Lamoreux, J. \& da Fonseca, G.A.B. (2004). Hotspots Revisited: Earth's Biologically Richest and Most Endangered Terrestrial Ecoregions. Cemex, Mexico City, Mexico.

Moreno, P.I.; Denton, G.H.; Moreno, H.; Lowell, T.V.; Putnam, A. E. \& Kaplan, M.R. (2015). Radiocarbon chronology of the last glacial maximum and its termination in northwestern Patagonia. Quaternary Sci Rev. 122, 233-249.

Murúa, R. \& González, L.A. (1982) Microhabitat selection in two Chilean cricetid rodents. Oecologia. 52: 12-15.

Murúa, R. \& González, L.A. (1986) Regulation of numbers in two Neotropical rodent species in southern Chile. Rev. Chil. Hist. Nat. 59: 193-200. 
544 Napolitano, C.; Johnson, W.W.; Sanderson, J.; O’Brien, S.J.; Rus Hoelzel, A.; Freer, R.; ... \&

545

546

547

548

549

550

551

552

553

554

555

556

557

558

559

560

561

562

563

564

565

566

567

568

569

570

571

572

573 Poulin, E. (2014) Phylogeography and population history of Leopardus guigna, the smallest American felid. Conserv Genet. 15: 631-653.

Olson, D.M. \& Dinerstein, E. (1998) The global 200: A representation approach to conserving the Earth's most biologically valuable ecoregions. Conserv Biol. 12: 502-515.

Omote, K.; Nishida, C.; Takenaka, T., \& Masuda, R. (2012). Temporal changes of genetic population structure and diversity in the endangered Blakiston's fish owl (Bubo blakistoni) on Hokkaido Island, Japan, revealed by microsatellite analysis. Zoo sci, 29: 299-304.

Osgood, W.H. (1943). The mammals of Chile, Vol. 30. University Chicago, Chicago.

Palma, R.E.; Rivera-Milla, E.; Salazar-Bravo, J.; Torres-Pérez, F.; Pardiñas, U.F.J; Marquet, P.A. \& Yates, T.L. (2005) Phylogeography of Oligoryzomys longicaudatus (Rodentia: Sigmodontinae) in temperate South America. J Mammal. 86: 191-200.

Palma, R.E.; Boric-Bargetto, D.; Torres-Pérez, F.; Hernández, C.E. \& Yates, T.L. (2012) Glaciation effects on the phylogeographic structure of Oligoryzomys longicaudatus (Rodentia: Sigmodontinae) in the Southern Andes. Plos One. 7: e32206.

Patterson, B. D., Meserve, P. L., \& Lang, B. K. (1990). Quantitative habitat associations of small mammals along an elevational transect in temperate rainforests of Chile. Journal of Mammalogy, 71: 620-633.

Patterson, B. D., P. Teta, and M F Smith. 2015 Genus Abrothrix Waterhouse, 1837. In Mammals of South America, Vol. 2: Rodents. J.L. Patton, U.F.J. Pardiñas, and G. D'Elía, eds. Pp. 109-126. Chicago: University of Chicago Press.

Peakall, R. \& Smouse, P.E. (2012). GenAlEx 6.5: genetic analysis in Excel. Population genetic software for teaching and research—an update. Bioinformatics. 28: 2537-2539.

Pearson, O.P. \& Smith, M.F. (1999). Genetic similarity between Akodon olivaceus and Akodon xanthorhinus (Rodentia: Muridae) in Argentina. J Zoo. 247: 43-52.

Pritchard, J.K.; Stephens, M. \& Donnelly, P. (2000) Inference of population structure using multilocus genotype data. Genetics. 155: 945-959.

Rabassa, J. \& Clapperton, C.M. (1990). Quaternary glaciations of the southern Andes. Quaternary Sci Rev. 9: 153-174. 
574 Rodríguez-Serrano, E.; Cancino, R.A. \& Palma, R.E. (2006) Molecular phylogeography of

575

576

577

578

579

580

581

582

583

584

585

586

587

588

589

590

591

592

593

594

595

596

597

598

599

600

601

602

603

604 Abrothrix olivaceus (Rodentia: Sigmodontinae) in Chile. J Mammal. 87: 971-980.

Segovia, R. A., M. F. Pérez \& L.F. Hinojosa (2012) Genetic evidence for glacial refugia of the temperate tree Eucryphia cordifolia (cunoniaceae) in southern South America. Am J Bot. 99: 121-129

Sersic, A.N.; Cosacov, A.; Cocucci, A.A.; Johnson, L.A.; Pozner, R.; Avila, L.J.; Sites, J.W. \& Morando, M. (2011). Emerging phylogeographical patterns of plants and terrestrial vertebrates from Patagonia.Biol J Linn Soc.103(2), 475-494.

Sikes, R.S. \& Gannon, W.L. The animal care and use committee of the American Society of Mammalogists. (2011) Guidelines of the American Society of Mammalogists for the use of wild mammals in research. J Mammal. 92: 235-253.

Tajima, F. (1989) Statistical method for testing the neutral mutation hypothesis by DNA polymorphism. Genetics. 123: 585-595

Van Oosterhout, C.; Hutchinson, W.F.; Wills, D.P. \& Shipley, P. (2004). MICRO-CHECKER: software for identifying and correcting genotyping errors in microsatellite data. Mol Ecol Notes. 4: 535-538.

Veblen, T.T. (2007) Temperate forests of the Southern Andean region (pp. 217-231). In: Veblen, T.T.; Orme, A.R. \& Young, K.R., editors. The physical geography of South America. Oxford University Press, Oxford, UK.

Vidal, M. A., Moreno, P. I., \& Poulin, E. (2012a). Genetic diversity and insular colonization of Liolaemus pictus (Squamata, Liolaeminae) in north-western Patagonia. Austral Ecol. 371: 67-77.

Vidal, M.A.; Ortiz, J.C.; Marín, J.C.; Poulin, E. \& Moreno, P.I. (2012b) Comparative phylogeography of two co-distributed species of lizars of the genus Liolaemus (Squamata: Tropiduridae) from Southern Chile. Amphibia-Reptilia. 33: 55-67.

Vilà, C.; Leonard, J.A.; Iriarte, A.; O’Brien, S.J.; Johnson, W.E. \& Wayne, R.K. (2004)

Detecting the vanishing populations of the highly endangered Darwin's fox, Pseudocalopex fulvipes. Anim Conserv. 7: 147-153.

Yahnke, C.; Johnson, W.; Geffen, E.; Smith, D.; Hertel, F.; Roy, M.S.; Bonacic, C.; Fuller, T.K.; Van Vulkenburgh, B. \& Wayne, R.K. (1996) Darwin's Fox: A distinct endangered species in a vanishing habitat. Conserv Biol. 10: 336-375. 
605 Young, A.G., \& Clarke, G.M. editors. (2000). Genetics, Demography and Viability of

606

607

608

609

610

611

612

613

614

615

616

617

618

619

620

621

622

623

624

625

626

627

628

629

630

631 Figure 1, Map of sampling sites; Study area in southern Chile, blue shade represents the Last

632 Glacial Maximum (LGM), green shade with black stripes in complete Chile indicates the

633 distribution of the Temperate Rainforest. On Chiloe Island in orange is delimitated the Cordillera

634 de Piuche. Black lines over the map indicates the result of the software Barriers, along with the

635 percentage of bootstrap of each barrier. The colors on the sampling point of the localities (study

636 area): Panguipulli (green), Valdivia (light blue), Bahia Mansa (gray), Las Quemas (Turquoise),

637 Senda Darwin (dark red), Cucao (Purple), Mininco (pink) and Alto Rio Ibañez (yellow);

638 represents localities that have mitochondrial sequences. Localities with light red color (Santa

639 Lucia, Palena and Rio Simpson) were only amplified for microsatellite markers.

640

641 Figure 2, Haplotype Network; Haplotype relationships of A. olivacea brachiotis. Each circle 642 represents a single haplotype sized in proportion of its frequency. The color code of each locality 643 is shown in the figure (BMLP; Bahía Mansa/La Picada and ARI; Alto Rio Ibañez). 
644

645 Figure 3. Relationship between Nei`s genetic distance and geographical distance in km among

646 populations of Abrothrix olivacea brachiotis (Mantel test of correlation, $r x y=0.386, p=0.01$ )

647

648 Figure 4, STRUCTURE analyses; Population structure of 187 individuals of Abrothrix olivacea 649 brachiotis inferred from Structure analyses. A) Structure with K=3, second highest probability.

650 B) Structure with $K=4$. C) Structure with $K=5$, highest probability with Evanno method.

651 Numbers represent the different sampling sites: 1 Panguipulli, 2 Valdivia, 3 Bahia Mansa, 4 La

652 Picada, 5 Las Quemas, 6 Senda Darwin, 7 Cucao, 8 Santa Lucia, 9 Palena, 10 Rio Simpson, 11

653 Mininco, 12 Alto Rio Ibañez.

654

655 Figure 5, Spatial population structure; GENELAND analyses with posterior probability isoclines.

656 Black dots represent the localities included in this study. Yellow indicates regions with the

657 greatest posterior probability of inclusion, and red areas show regions with the lower

658 probabilities of inclusion. Probabilities are proportional to the degree of coloring. A) Cluster

659 number 1 with populations of Valdivia, Bahia Mansa, Las Quemas, La Picada, Panguipulli and

660 Senda Darwin (Chiloe); B) Cluster number 2 with populations of Panguipulli and Cucao; C)

661 Cluster number 3 with populations of Santa Lucia, Palena, Rio Simpson, Mininco and Alto Rio

662 Ibañez.

\section{Table legends:}

664

665 Table 1, Genetic diversity; N, Number of individuals, $\mathrm{H}_{\mathrm{o}}$, observed heterozygosity; $\mathrm{H}_{\mathrm{S}}$, expected

666 heterozygosity; A, Number of alleles; Ar, Number of alleles with rarefaction (20 genes); $\mathrm{G}_{\text {IS, }}$,

667 Inbreeding coefficient; Ne, Effective population size. The two upper columns represent the

668 grouping per sampling localities and per genetic clusters (according to Structure analysis).

669

670

671

672

673 Supplementary Material 
674 Table S1. Localities sampled; List of specimens analyzed and geographic coordinates, with the 675 genetic marker used (Microsatellite STR and/or mitochondrial)

676 Table S2. GenBank accessions for microsatellite primer sets.

677 Table S3, Pairwise differentiation $\mathrm{F}_{\mathrm{ST}}$; Pairwise comparison between population above the 678 diagonal and $p$ values below the diagonal. $(*=p>0.01)$

679 


\section{Figure 1}

Map of sampling sites

Study area in southern Chile, blue shade represents the Last Glacial Maximum (LGM), green shade with black stripes in complete Chile indicates the distribution of the Temperate Rainforest. On Chiloe Island in orange is delimitated the Cordillera de Piuche. Black lines over the map indicates the result of the software Barriers, along with the percentage of bootstrap of each barrier. The colors on the sampling point of the localities (study area): Panguipulli (green), Valdivia (light blue), Bahia Mansa (gray), Las Quemas (Turquoise), Senda Darwin (dark red), Cucao (Purple), Mininco (pink) and Alto Rio Ibañez (yellow); represents localities that have mitochondrial sequences. Localities with light red color (Santa Lucia, Palena and Rio Simpson) were only amplified for microsatellite markers. 


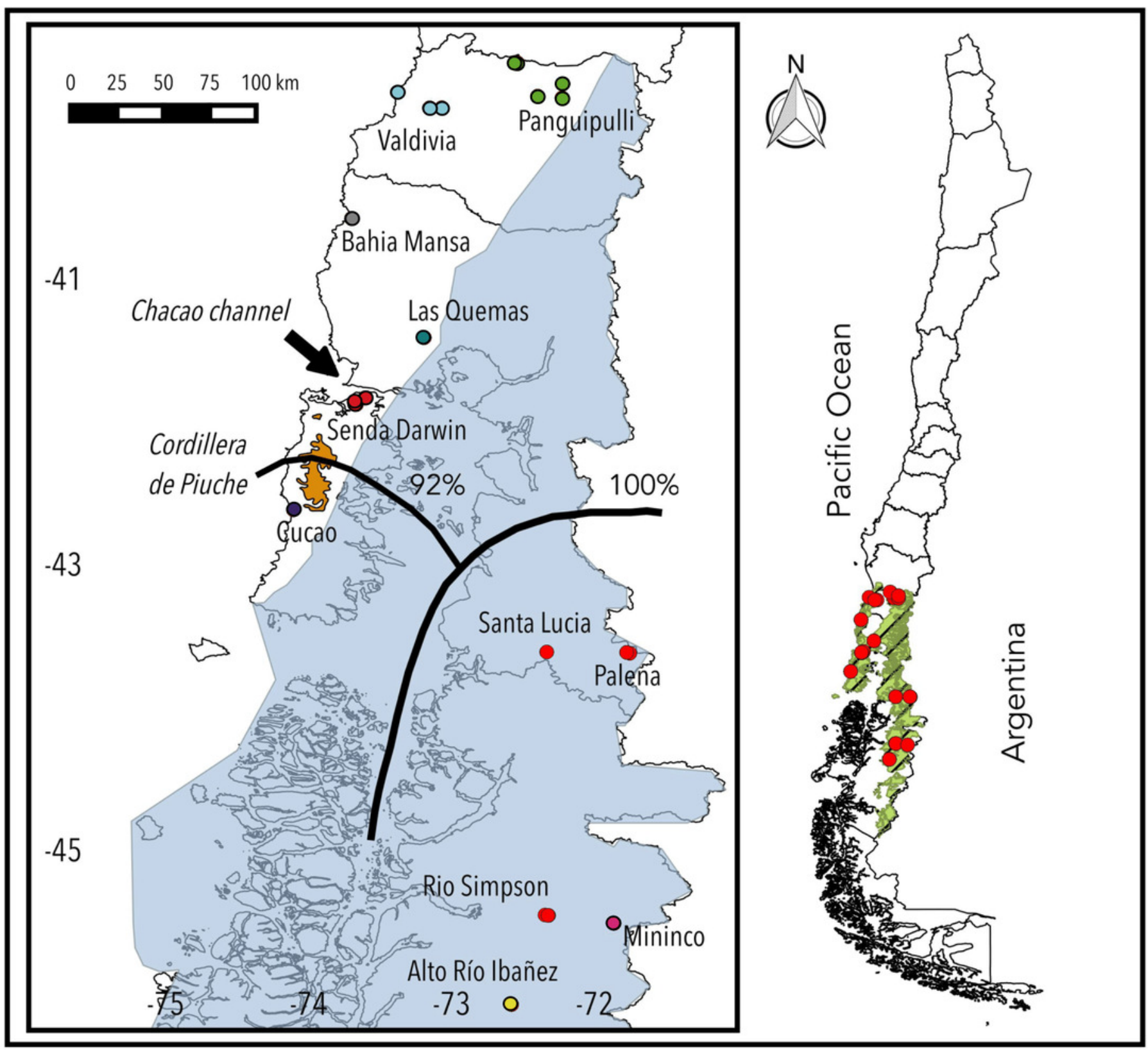


Figure 2

Haplotype Network

Haplotype relationships of $A$. olivacea brachiotis. Each circles represent a single haplotype sized in proportion of its frequency. The color code of each locality its shown in the figure (BMLP; Bahía Mansa and ARI; Alto Rio lbañez).

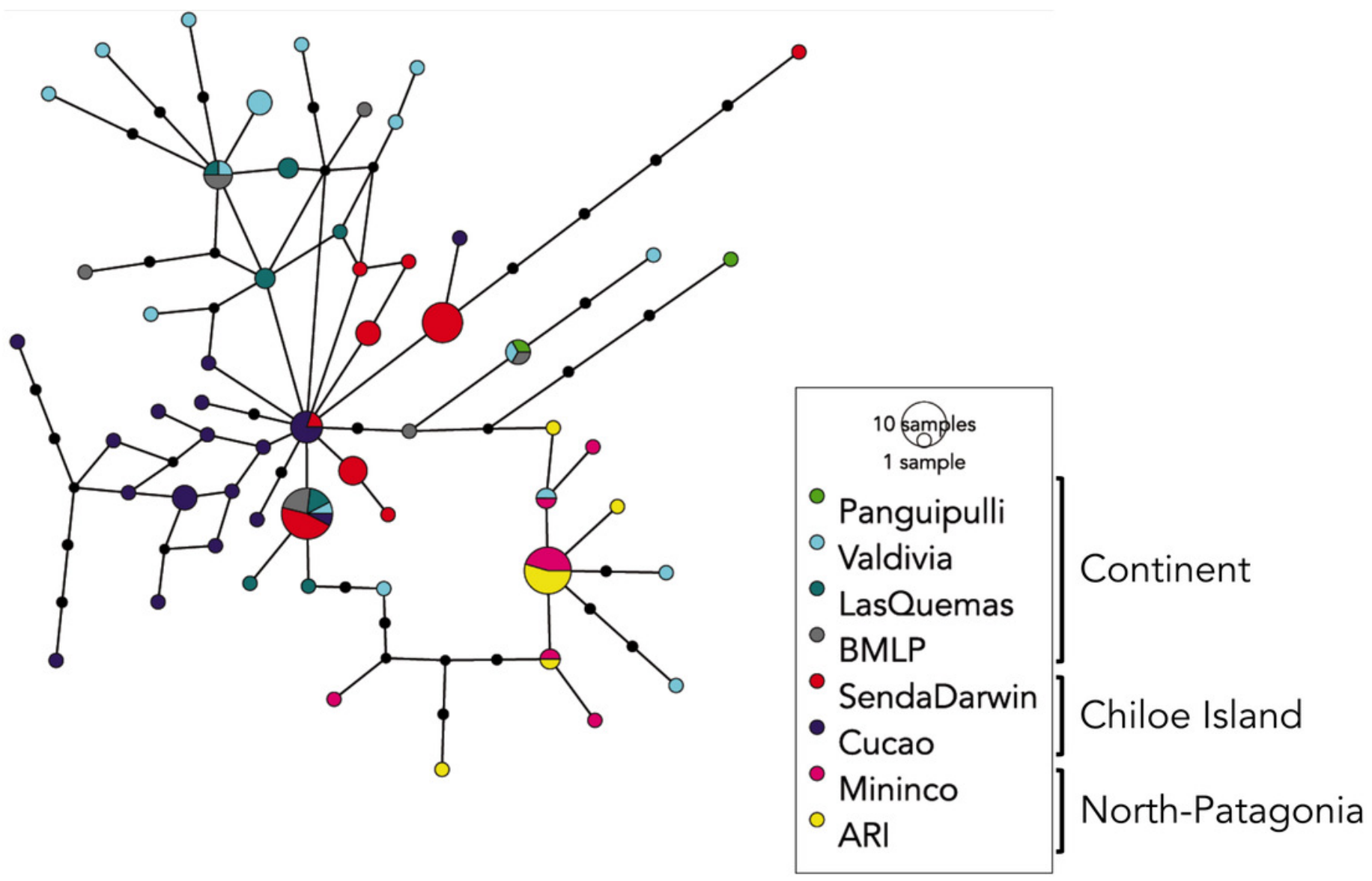


Figure 3

Mantel test

Relationship between Nei`s genetic distance and geographical distance in km among populations of Abrothrix olivacea brachiotis(Mantel test of correlation, $r x y=0.386, p=0.01$ )

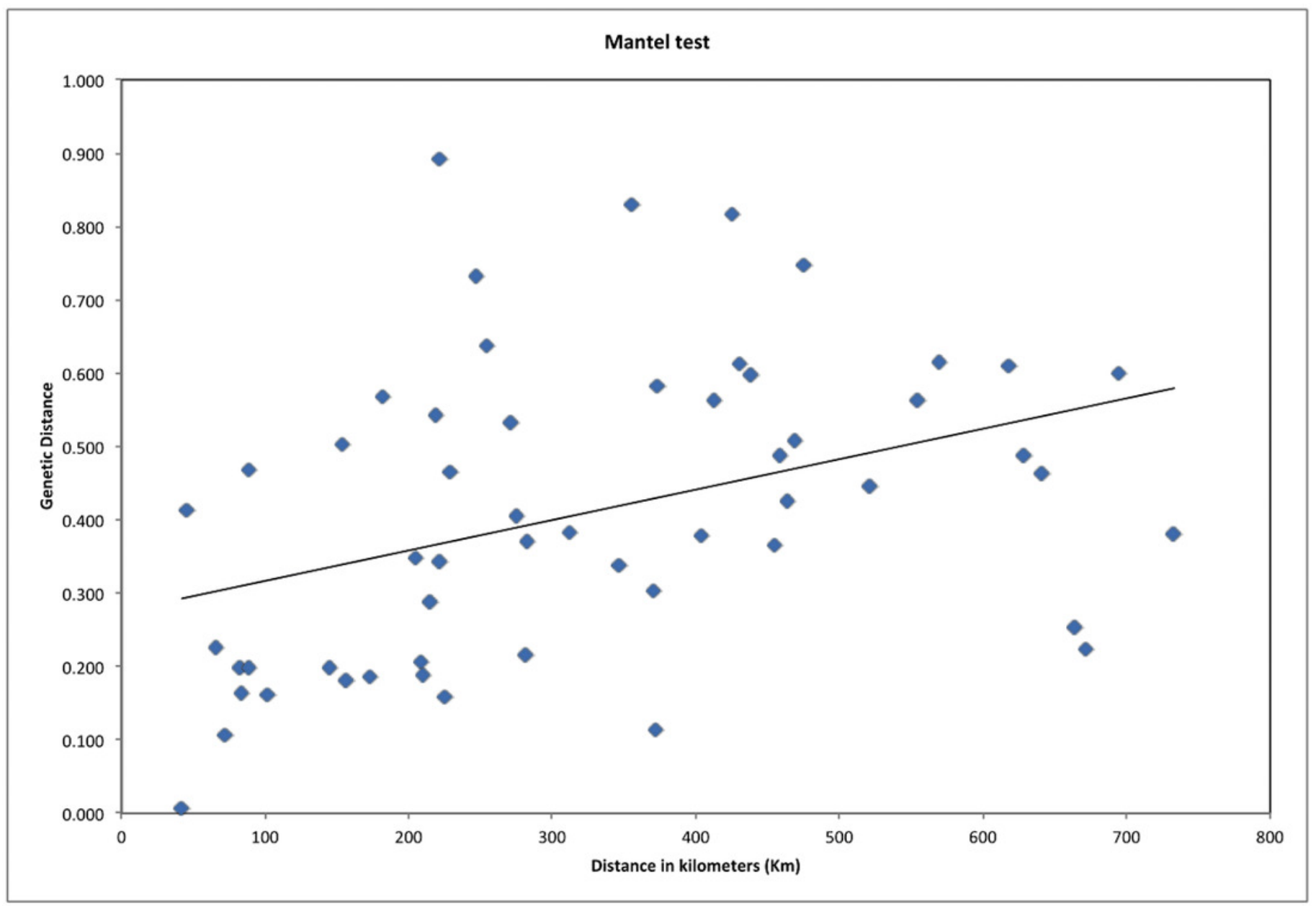




\section{Figure 4}

STRUCTURE analyses

Population structure of 187 individuals of Abrothrix olivacea brachiotis inferred from

Structure analyses. A) Structure with $K=3$, second highest probability B) Structure with $K=4$

C) Structure with $K=5$, highest probability with Evanno method. Numbers represent the different sampling sites: 1 Panguipulli, 2 Valdivia, 3 Bahia Mansa, 4 La Picada, 5 Las Quemas, 6 Senda Darwin, 7 Cucao, 8 Santa Lucia, 9 Palena, 10 Rio Simpson, 11 Mininco, 12 Alto Rio Ibañez.

A)

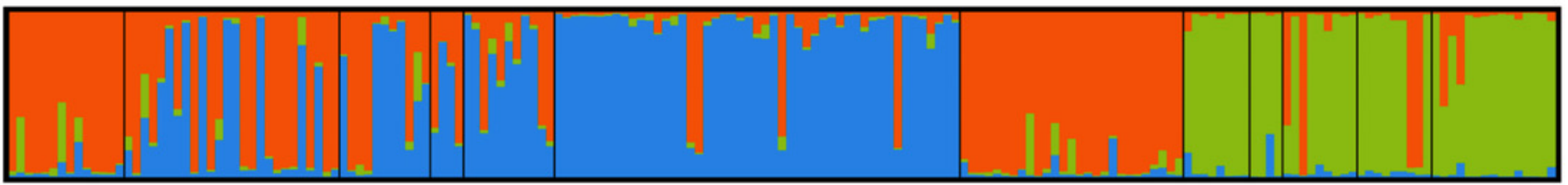

B)

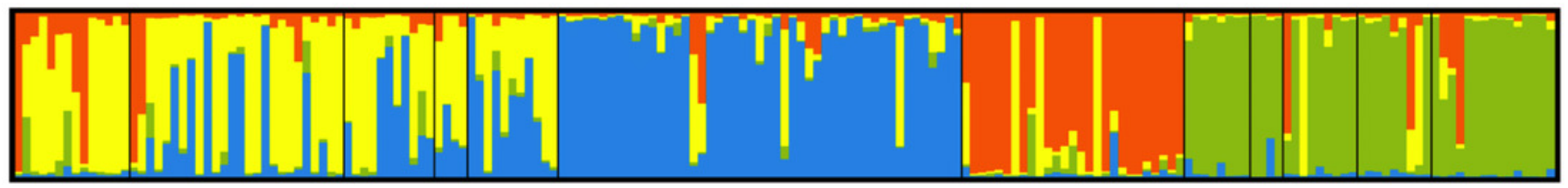

C)

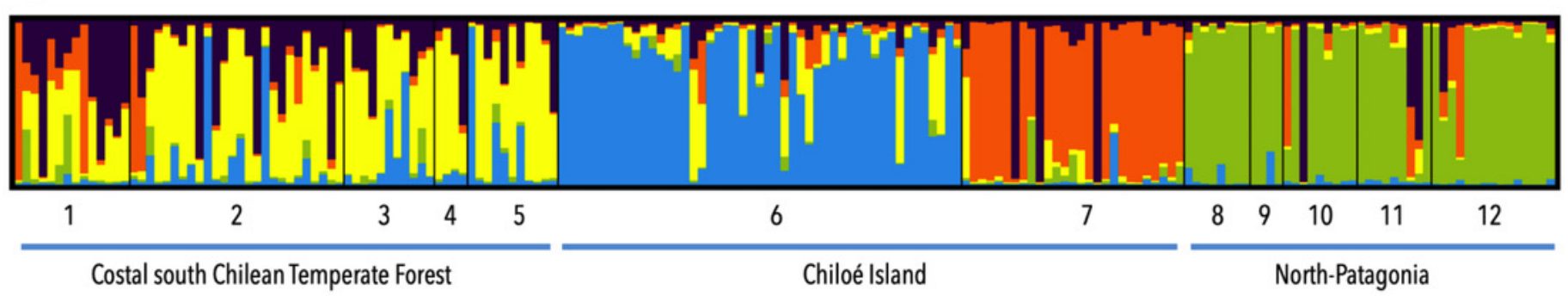




\section{Figure 5}

Spatial population structure

GENELAND analyses with posterior probability isoclines. Black dots represent the locality presents in this study. Yellow indicates regions with he greatest posterior probability of inclusion, and red areas shows region with lower probabilities of inclusion, this proportional to the degree of coloring. A) Cluster number 1 with populations of Valdivia, Bahia Mansa, Las Quemas, La Picada, Panguipulli and Senda Darwin (Chiloe); B) Cluster number 2 with populations of Panguipulli and Cucao; C) Cluster number 3 with populations of Santa Lucia, Palena, Rio Simpson, Mininco and Alto Rio Ibañez.

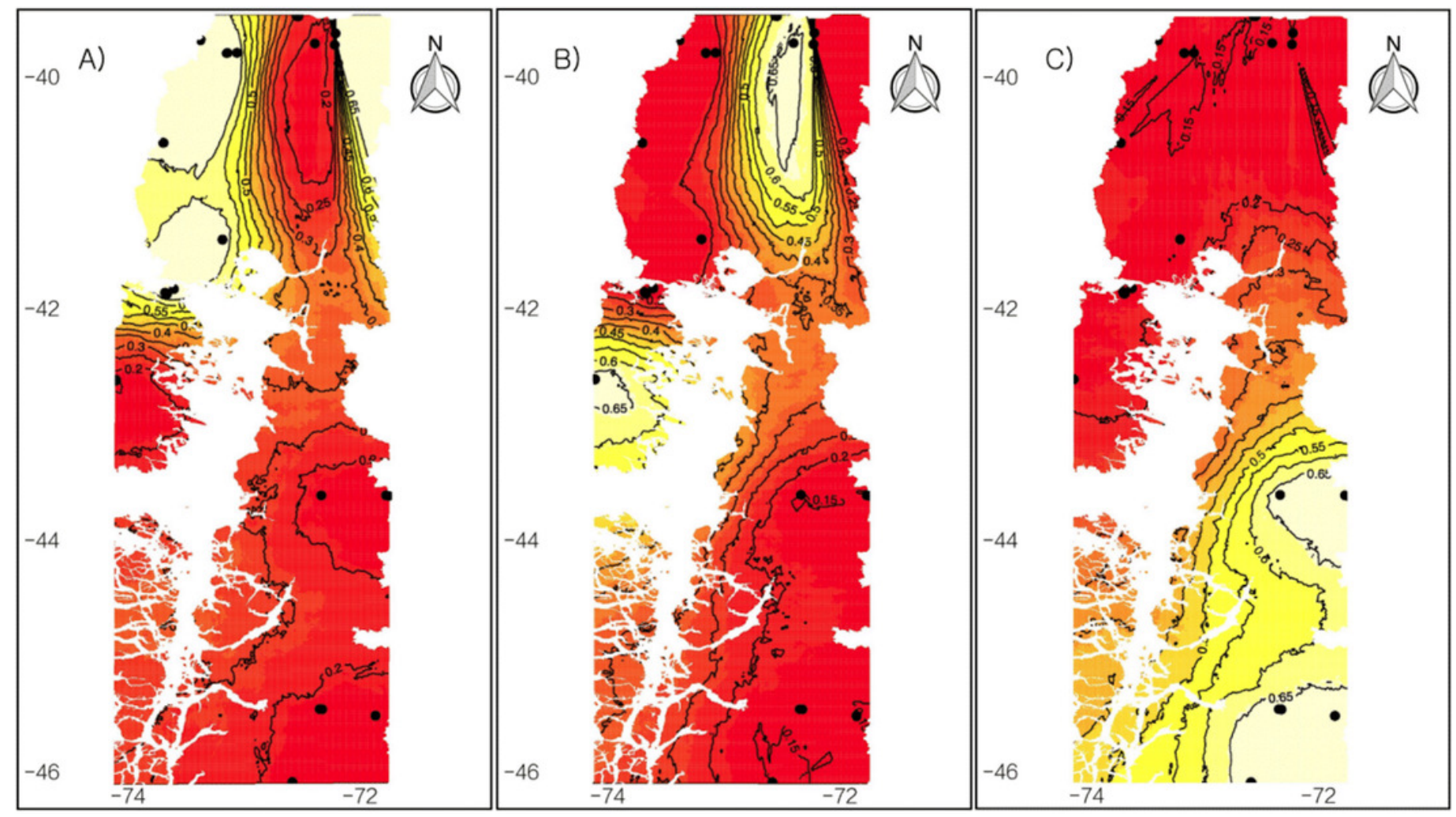




\section{Table $\mathbf{1}$ (on next page)}

Genetic diversity

$N$, Number of individuals, $H_{0}$, observed heterozygosity; $H_{s}$ expected heterozygosity; $A$, Number of alleles; Ar, Number of alleles with rarefaction (20 genes); $\mathrm{G}_{\mathrm{IS}}$, Inbreeding coefficient; Ne, Effective population size. The two upper columns represent the grouping per sampling localities and per genetic clusters (according to Structure analysis). 
$1 \quad$ Table 1

2

\begin{tabular}{|c|c|c|c|c|c|c|c|c|c|c|c|c|}
\hline & \multicolumn{5}{|c|}{ Sampling locations } & \multicolumn{7}{|c|}{ Genetic clusters } \\
\hline Population & $\mathrm{N}$ & Ho & $\mathrm{He}$ & A & $\mathrm{Ar}$ & $\mathrm{N}$ & A & $\mathrm{Ar}$ & Ho & Hs & Gis & $\mathrm{Ne}$ \\
\hline Panguipulli & 14 & 0.835 & 0.887 & 12.33 & 10.45 & \multirow{5}{*}{66} & \multirow{5}{*}{20.75} & \multirow{5}{*}{10.53} & \multirow{5}{*}{0.776} & \multirow{5}{*}{0.878} & \multirow{5}{*}{0.117} & \multirow{5}{*}{$\begin{array}{c}683.3 \\
(313.9-\infty)\end{array}$} \\
\hline Valdivia & 26 & 0.79 & 0.865 & 14.83 & 10.09 & & & & & & & \\
\hline $\begin{array}{c}\text { Bahia } \\
\text { Mansa } \\
\left(\mathrm{BH} \_\mathrm{M}\right)\end{array}$ & 11 & 0.718 & 0.844 & 7.67 & 7.2 & & & & & & & \\
\hline La Picada & 4 & 0.562 & 0.844 & 4.33 & 4.33 & & & & & & & \\
\hline Las Quemas & 11 & 0.775 & 0.84 & 9.75 & 8.57 & & & & & & & \\
\hline $\begin{array}{c}\text { Senda } \\
\text { Darwin }\end{array}$ & 49 & 0.748 & 0.809 & 17 & 8.7 & 49 & 17 & 8.7 & 0.748 & 0.809 & 0.076 & $\begin{array}{c}274.9 \\
(164.1- \\
762.1)\end{array}$ \\
\hline Cucao & 27 & 0.848 & 0.979 & 14.33 & 9.49 & 27 & 14.33 & 9.49 & 0.843 & 0.879 & 0.041 & $\begin{array}{c}54(41.1- \\
76.4)\end{array}$ \\
\hline $\begin{array}{c}\text { Palena Santa } \\
\text { Lucia }\end{array}$ & 12 & 0.735 & 0.78 & 7.5 & 6.08 & \multirow{4}{*}{45} & \multirow{4}{*}{15.66} & \multirow{4}{*}{9.13} & \multirow{4}{*}{0.759} & \multirow{4}{*}{0.825} & \multirow{4}{*}{0.08} & \multirow{4}{*}{$\begin{array}{c}113.2 \\
(82.4- \\
174.4)\end{array}$} \\
\hline $\begin{array}{c}\text { Rio } \\
\text { Simpson }\end{array}$ & 9 & 0.749 & 0.831 & 8.08 & 8.08 & & & & & & & \\
\hline Mininco & 9 & 0.762 & 0.829 & 7.67 & 7.5 & & & & & & & \\
\hline $\begin{array}{l}\text { Alto Rio } \\
\text { Ibañez }\end{array}$ & 15 & 0.771 & 0.771 & 8.42 & 7.5 & & & & & & & \\
\hline
\end{tabular}

